\title{
EN BÚSQUEDA DE LA IDENTIDAD SOCIAL DEL INGENIERO: UNA TRAYECTORIA DE CONSTRUCCIÓN DE IDENTIDAD PROFESIONAL EN COLOMBIA EN MEDIO DE LA MODERNIZACIÓN CAPITALISTA (1848-1929)*
}

\section{THE SEARCH FOR THE SOCIAL IDENTITY OF THE ENGINEER: A PATH OF CONSTRUCTION OF PROFESSIONAL IDENTITY IN COLOMBIA IN THE MIDST OF CAPITALIST MODERNIZATION (1848-1929)}

\author{
Rodrigo Hernán ToRrejano-Vargas** \\ HenRY BoCANEGRA-ACOSTA ***
}

\begin{abstract}
Resumen
Objetivo. Ilustrar el proceso histórico que condujo al reconocimiento y a la legitimación social y profesional de la ingeniería, así como la construcción de la identidad social de los ingenieros en varios países de Latinoamérica, particularmente en Colombia. Metodología. Parte de la perspectiva del colectivismo metodológico, en el que las condiciones materiales y culturales son fundamentales para contextualizar y explicar los procesos de construcción de identidad social. Resultados. La profesión de ingeniero adquirió relevancia social, económica y política desde que el Estado la adoptó como la profesión del futuro, esa sin la cual ningún país podría alcanzar el desarrollo y progreso material. Conclusion. El ingeniero adquirió una imagen social positiva relacionada con el espíritu racionalista y pragmático de la época y de su oficio.
\end{abstract}

Palabras clave: ingeniero, profesión, identidad social, imagen positiva, adalid de la modernización

\begin{abstract}
Objective. To illustrate the historical process that led to the recognition of social and professional legitimation of engineering as well as the construction of social identity for engineers in Latin America, particularly in Colombia. Methodology. It starts from the perspective of methodological collectivism, in which material and cultural conditions are fundamental to contextualize and explain the processes of construction of social identity. Results. The profession of engineer acquired social, economic and political relevance since the State adopted it as the profession of the future, without which no country could achieve material development and progress. Conclusion. The engineer acquired a positive social image related to the rationalist and pragmatic spirit of the time and to his purpose.
\end{abstract}

Key words: engineer, profession, social identity, positive image, leader of modernization

\footnotetext{
*Artículo en colaboración, producto de la investigación desarrollada por los autores desde sus grupos y proyectos de investigación institucional: Derechos, movimientos sociales y políticas públicas del Grupo de Investigaciones Socio Jurídicas del Centro de Investigaciones Socio Jurídicas de la Universidad Libre, Sede Principal, y Política pública, identidad y representaciones sociales de las profesiones en Colombia en el marco de la vida republicana, siglos XIX y XX, Grupo Derecho Público y Sociedad de la Corporación Universitaria Republicana

** Corporación Universitaria Republicana. Bogotá, D.C., Colombia. E-mail: rtorrejano@gmail.com

(D) orcid.org/0000-0002-2672-9831 Google Scholar

*** Universidad Libre de Colombia. Bogotá, D.C., Colombia. E-mail: henrybocanegra1992@yahoo.es

(D) orcid.org/0000-0001-7623-7483 Google Scholar
} 


\section{Introducción}

El artículo responde a la pregunta: ¿cuál fue el proceso histórico mediante el cual la ingeniería adquirió relevancia estratégica y los ingenieros forjaron una personalidad grupal durante la formación del Estado-nación en sinuoso tránsito al capitalismo (1848-1929)? La respuesta sugerida es que la búsqueda de fórmulas para el desarrollo económico nacional llevó a priorizar la educación pragmática y útil en lugar de la formación humanista y teológica, que en Colombia estuvo sumamente asociada con la conformación del perfil primario exportador y su posterior tránsito hacia una economía industrializada dirigida por el Estado (Bertola y Ocampo, 2016), y esto, a su vez, sirvió para legitimar al profesional que se autodefinió como la personificación de la modernización y el adalid del progreso, para lo cual el texto está organizado en cinco secciones: la primera aborda la descripción del panorama de la ingeniería y el ingeniero en algunos países latinoamericanos; la segunda hace referencia a la delimitación de la imagen positiva del ingeniero en dichos países; la tercera alude al contexto cultural y económico en el que se posiciona la ingeniería y al ingeniero colombiano y, la cuarta y quinta abordan la explicación de los rasgos sobresalientes de la identidad colectiva del ingeniero en Colombia, haciéndolo desde la perspectiva del colectivismo metodológico en el que las condiciones materiales y culturales son fundamentales para contextualizar y explicar los procesos de construcción de identidad social.

\section{Discusión}

\section{La búsqueda de reconocimiento social de la ingeniería en Latinoamérica}

La profesión desde la perspectiva funcionalista y utilitarista es una representación del orden social que delimita un conjunto de habilidades, técnicas, instrumentos, actitudes, valores y símbolos que interactúan a favor del perfeccionamiento de la relación con la naturaleza y torna más livianas y fluidas las condiciones de vida de la humanidad, lo que conlleva a que el individuo adquiera un beneficio económico de su conocimiento (Durkheim, 1893; Burke, 2013; Smith, s.f.; Spencer, s.f.).

Esta aproximación práctica es la que históricamente proporciona legitimidad a la profesión de ingeniero, en el sentido de que la existencia de un consenso intelectual y político, en amplios sectores letrados y líderes de la sociedad, acerca de la relevancia de un ejercicio laboral que requiere de una alto grado de sofisticación teórica y práctica en función de la búsqueda de bienes, servicios y rentas que faciliten la vida colectiva y el avance de las fuerzas productivas y los métodos de producción, en la perspectiva del posicionamiento de la nación en un concierto de competencia y relaciones internacionales asimétricas. 
Esta legitimidad profesional del moderno ingeniero, puesta en el horizonte del principio vital de la preservación de la humanidad organizada en naciones, puso de presente que la consecución del indicado objetivo general de desarrollo socioeconómico estaba muy relacionado con la educación de un sujeto histórico universitario que mirara en dirección de la construcción de un puente entre el universo abstracto de la teoría con el cosmos real de los retos y los problemas que presentaba el desarrollo económico y tecnológico.

Esta pretensión cultural y económica de la moderna economía de mercado traería implícito el cuestionamiento del patrón educativo occidental confiado a la enseñanza de las humanidades y la teología y, de otra parte, el evidente entusiasmo por una educación universitaria menos “espiritual”, en diálogo con un mundo más pragmático, interrelacionado, comunicado, poblado, urbano y comercial (Silva, 2007; Le Goff, 2008). En España, la localización temporal y fáctica de este proceso nos lleva hasta finales del siglo XVI en el reinado de Isabel; en Latinoamérica, como se detallará más adelante, la trayectoria puede rastrearse desde los albores del siglo XVIII -ascenso de la casa Borbónica al poder regio y el siglo XIX con la formación del Estado-nación y su integración al mercado mundial.

Pero la legitimidad social de la profesión de ingeniero, ofrecida por el propio desarrollo de la economía capitalista, habría sido insuficiente sin la erosión de valores medievales y antiguos que asociaban la ingeniería con el trabajo manual y mecánico propio de sectores sociales marginales, un oficio, por donde se le mirara, innoble. Este segundo proceso de otorgamiento de mérito estuvo ligado con la fuerza que tomó la visión pragmática de la burguesía europea y, digamos, los polifacéticos empresarios latinoamericanos (Dávila, 2003; Bertola y Ocampo, 2016) en favor de la uniformidad social de los oficios.

En España esta cruzada la notamos a partir de los albores del siglo XVIII. Felipe V ennoblece y distingue las artes industriales, eximiendo a sus trabajadores del estigma de villanía (Valbuena, 1996), después de lo cual concedería a la ingeniería una membrecía de hidalguía moderna: práctica y utilitaria. Él fundó el 21 de abril de 1711 el Cuerpo de Ingenieros de los Ejércitos, Plazas, Puertos y Fronteras de Su Majestad (Valbuena, 1996). Este doble proceso de legitimización de la ingeniería en España se complementaría con la promoción de sociedades amigas de los estudios prácticos y la fundación de instituciones educativas del ramo (Valbuena, 1996; Silva, 2007), sin descontar que el Estado pasó a convertirse en fuente principal de contratación laboral.

En Latinoamérica los dirigentes políticos de los nuevos estados trabajaron en la misma dirección. En México, el primer antecedente de participación estatal en la conformación del cuerpo de ingenieros viene, desde luego, ligado a la política reformista borbónica, cuando se funda el Real Seminario de Minería en 1792, renombrándolo Colegio de Minería después de la emancipación, que a la postre, a partir de la expulsión de los franceses en la década de 1860, 
En búsqueda de la identidad social del ingeniero: una trayectoria de construcción de identidad profesional en Colombia...

se conoció como Escuela Especial de Ingenieros, que con la reforma educativa de 1883 adoptó el nombre de Escuela Nacional de Ingenieros y el establecimiento de la Facultad de Ingeniería de la Universidad Nacional (De la Torre, 2002; Tanamachi y Ramos, 2015). A lo que se sumaría la conformación y organización formal del gremio de ingenieros en 1868 con la Sociedad de Ingenieros Civiles y Arquitectos de México (De la Torre, 2002; Tanamachi y Ramos, 2015). Aunque, a diferencia de España no hubo un Cuerpo como tal o una dependencia específica que los organizara y contratara, el Estado nunca dejó desempeñar un destacado rol de promoción y fortalecimiento de la profesión durante todo el siglo XIX (Domínguez, 2013).

En Chile, en cambio, podemos notar que estuvo más cerca de lo que dispusieron los españoles. La predica oficial priorizó el desempeño profesional al servicio del Estado, por eso él fue una de las principales fuentes de empleo cuando creó el Cuerpo de Ingenieros Civiles por la Ley General de Caminos de 1842 (Parada, 2011). En este país la corporativización de los ingenieros se dio en 1888 con la fundación del Instituto de Ingenieros, que, como en México, $y$, en general en todo el continente, se puso como meta permear la sociedad nacional con propaganda profesional sistematizada que diera a conocer la fundamentación académica del ejercicio del oficio, que sería igual a indicar que el interés primordial siempre fue conferirle legitimidad a su actividad profesional proyectando la figura del trabajador erudito especializado, consciente de que su validez funcional estribaría en la capacidad de estar al tanto y aplicar los avances de la ciencias exactas y las novedades de la tecnología. La idea era presentarse ante la comunidad nacional como adalides de la modernización (Parada, 2011).

En Perú, la historia discurrió en dirección idéntica, en el entendido de que el Estado atendió el requerimiento nacional de impulsar la profesionalización ingenieril desde mediados del siglo XIX bajo la premisa de contar con capital humano capacitado para concretar los planes de explotación de los recursos naturales de una economía cada vez más integrada al concierto mundial, que de paso ilustraba, a juicio de Contreras y Cueto (2008), la proyección del patrón de transformación práctico y cultural instaurado en el régimen borbónico, "es decir, una ciencia utilitaria orientada a explorar las posibilidades económicas de los territorios" (Contreras y Cueto, 2008, p. 642). Las dos primeras acciones del Gobierno peruano en favor de la promoción de la enseñanza y la profesionalización de la ingeniería fueron la creación de la Comisión Central de Ingenieros Civiles en 1852 y la fallida Escuela Central de Ingenieros Civiles en 1853, siguiéndoles la inauguración de la Escuela Especial de Construcciones Civiles y de Minas en 1876 (López, 2012)

Esta sucinta trayectoria dieciochesca y decimonónica de la legitimación de la ingeniería en Latinoamérica, indica que el factor clave que la caracterizó fue el apremio por sortear el reto del desarrollo económico en un esquema liberal de producción y exportación de bienes primarios hacia el mercado europeo y norteamericano, que pudiera borrar las frustraciones de las primeras seis o siete décadas del siglo, "que habían sido, en general, decepcionantes 
en lo que al crecimiento económico, si bien aquí y allá (...) se hicieron modestos progresos materiales y de organización” (Glade, 1991, p. 1; Ocampo, 1998, 2015).

Este celo económico vinculado con la ingeniería, igualmente tiene un fuerte y estrecho lazo con el positivismo en la educación, en la que se advierte: "Primeramente, el énfasis en el aprendizaje enciclopédico (...) en segundo lugar, el creciente sesgo favorable a lo científico y práctico en contraposición a los estudios humanísticos, y, en tercer lugar, la adhesión al secularismo" (Hale, 1991, p. 16). Dicho sentido liberal, utilitarista y pragmático que fluía por el mundo capitalista de las naciones de Europa occidental, Estados Unidos y Latinoamérica, termina siendo un componente que encaja en la lógica del mercado y la renta que reclama la sociedad y el Estado. Tema que abordaremos con más detalle en el siguiente acápite.

\section{La cruzada identitaria del ingeniero latinoamericano}

Como se indicó al principio del subtítulo anterior, la ingeniería moderna en Iberoamérica tiene un pasado que la vincula con el espíritu ilustrado reformador de la dinastía Borbón en España que emerge con Felipe V en la firma del Tratado de Utrecht el 11 de abril de 1713 (Torrejano, 2012), en pos de la reanimación económica e institucional de un imperio subdesarrollado y moribundo (Lynch, 1987).

Este espíritu ilustrado de tono práctico y naturalista acarrea la confirmación de una polémica de data anterior en Europa occidental, una que nos transporta hasta los albores de la Baja Edad Media y el espíritu chartrense (Le Goff, 2008), consistente en la exaltación académica y funcional de las disciplinas que componían el quadrivium de la escuela palatina carolingia: la aritmética, la geometría y la física (no contamos intencionalmente con la música, integrante final de la composición), basada en la recuperación de un acervo intelectual que había permanecido en estado de hibernación y la adopción de una metodología de investigación científica amparada en la experimentación. En síntesis, un "espíritu de curiosidad, de observación, de investigación que, alimentado por la ciencia greco árabe, había de florecer con brillo singular” (Le Goff, 2008, p. 61).

Este espíritu de observación, experimentación, curiosidad y aplicación contenía una segunda revolución cultural, de fuerte imbricación con la legitimización de la ingeniería: la reivindicación del trabajo manual o mecánico, que todavía cargaba a cuestas la impronta innoble y servil de su oficio, por tratarse del quehacer propio de los marginados (Le Goff, 2008), pero que desde el siglo XII experimentará la rehabilitación de su imagen: "Es el redescubrimiento del Homo Faber, cooperador de la creación con Dios y con la naturaleza” (Le Goff, 2008, p. 68).

Esta fue la línea educativa y cultural que viajó a través del tiempo y el espacio hasta la conformación y asentamiento del Estado-nación en Latinoamérica. Los gobernantes nacionales 
En búsqueda de la identidad social del ingeniero: una trayectoria de construcción de identidad profesional en Colombia...

contemporizaron con la proyección pragmática del espíritu chartrense en aras del fomento de la enseñanza aplicada de la ciencia exacta y natural, universo en el que matricularían a la ingeniería, no sin dejarse escuchar voces amigas de conferirles a los ingenieros un alto tono teórico a su formación académica.

En consonancia con el desenvolvimiento de esta ruta pragmática los ingenieros latinoamericanos anhelaban poner sus conocimientos al servicio de la empresa privada y el Estado, y buscaban abrirse camino en la modernización económica liberal, "donde estaba todo por hacerse" (Parada, 2011, p. 13); compromiso que se traducía en la salida al mercado laboral para conseguir empleo, en el que todavía la oferta de trabajo era reducida y tenían que competir con los ingenieros extranjeros, quienes eran preferidos por los contratistas (Parada, 2011).

Esta asimetría en la contratación adquirió ribetes más dramáticos cuando los ingenieros extranjeros siempre tuvieron una mejor ubicación y salario en la empresa contratista (Parada, 2011). La razón aducida por los empresarios fue que aún no se contaba con profesionales domésticos con experiencia en el diseño y la construcción de obras complejas de infraestructura: ferrocarriles, puertos, canales de navegación, pero independientemente de la validez del argumento de selección laboral, esta doble asimetría propició la creación de un tenso ambiente social entre uno y otro grupo profesional. La división pronto se convertiría en oposición y segmentación social que iría a alimentar el sentido de identidad profesional del ingeniero latinoamericano.

De esta manera, la identidad profesional acogería un sutil sentimiento nacionalista aferrado al imaginario de su función social en la generación de riqueza y progreso para la nación, y a la idónea formación académica que recibieron en el sistema educativo nacional. El efecto más sensible de esta disposición nacionalista consistió en la fundación de asociaciones propias o corporaciones que trabajaron por la creación y la difusión de una imagen de idoneidad y confiabilidad profesional (Domínguez, 2013; Salerno, 2015).

En sincronía con el espíritu nacionalista ingenieril fecundado en la matriz de la modernización capitalista nacional y el enfoque educativo pragmático basado en la ciencia aplicada, estuvo cocinándose el componente antropológico de la identidad profesional en defensa de la inquebrantable misión histórica de traer la modernidad al continente y sentirse modernos, esto es, encontrarse "en un entorno que nos promete aventuras, poder, alegría, crecimiento, transformación de nosotros y del mundo y que, al mismo tiempo, amenaza con destruir todo lo que tenemos, todo lo que sabemos, todo lo que somos" (Berman, 1989, p. 1), que los impelía a cambiar el mundo como reza en esta anotación formulada por el ingeniero mexicano Manuel Torres Torija el 25 de noviembre de 1900: 
hoy, en resumen, la ingeniería como profesión de engrandecimiento y de prosperidad para los pueblos, es el Deux Ex machina simbólico que, agigantándose en su lucha pujante con las dificultades, va a la cabeza de los factores de progreso, sembrando donde quiera el adelanto, brindando la fraternidad y el consorcio, rompiendo las tramas de la rutina y dominando bajo la majestad de su imperio sin límites las fuerzas todas de la naturaleza. (Manuel Torres Torija como se citó en Domínguez, 2013, p. 56)

Punto de vista que se corrobora con las palabras pronunciadas por el Ministro de Instrucción del Perú, Manuel Odriozola, en la Escuela de Ingenieros en 1876 al anotar acerca de su misión institucional esta convocatoria:

está llamada a prestar, en época muy próxima, grandes y útiles servicios a la nación (...) La explotación inteligente de tan valiosos productos minerales requería indispensablemente la fundación de un establecimiento a la vez científico y práctico (...) fomentando al mismo tiempo que la utilidad y bienestar de los particulares, el incremento de la riqueza nacional. (Manuel Odriozola como se citó en López, 2012, p.28).

Entonces, lo que apreciamos es que los propios ingenieros se encontraban inmersos en un proceso de modelamiento de la representación concreta de un estereotipo social asociado con las presuntas mieles de la transformación del mundo y la nación; estaban ensamblando una imagen en la que se ven como un grupo social especializado que simboliza la cristalización de una revolución universal. En estricto sentido antropológico, dejan entrever su proyección de hombre que trabaja, transforma y aplica; el hombre de los algoritmos que supera al hombre de la gramática y la retórica que malgasta la energía vital en la polémica altisonante y el conflicto social, político e ideológico, que implica, en el fondo, la expansión de la poderosa fuerza liberal de "culto al progreso material (...) profesado por la élite gobernante e intelectual" (Hale, 1991, p. 7).

La interiorización y la exteriorización de la imagen del ingeniero como hombre moderno e impulsor de la modernidad, apegado a la gramática positivista que se abalanza sobre América Latina, fue un componente que acarreó un interesante juego dialéctico en el seno de los profesionales y la fisonomía de la misma ocupación, puesto que en las últimas décadas del siglo XIX y las primeras dos o tres del siglo XX, se desarrollaría una metamorfosis de su representación social: el transitó de una identidad estrechamente vinculada con el inconformismo proveniente de la preferencia que tenían los empresarios y el Estado por contratar ingenieros extranjeros (asimetría ocupacional), a una identidad dominada por la certeza de pertenecer a una nueva "nobleza" en la que se pudo establecer una equivalencia de hidalguía y ciencia aplicada. Por 
En búsqueda de la identidad social del ingeniero: una trayectoria de construcción de identidad profesional en Colombia...

eso, no extraña que el título de ingeniero viniera con mejoramiento del estatus social, según se desprende de la disertación hecha en 1909 por el ingeniero mexicano Daniel Olmedo:

\begin{abstract}
el mencionado título nos coloca un poco más altos en la escala social y muchas perdonas desearían tenerlo, no por la posesión de conocimientos propios a cada profesión, ni por la satisfacción de ejercitar determinadas facultades, sino por aparecer en público con el nombre aumentado por la anteposición de la palabra Ingeniero, Doctor o Licenciado. (Daniel Olmedo como se citó en Domínguez, 2013, p. 56)
\end{abstract}

Por otra parte, es imposible resistirse a la tentación de explicar que a uno y otro extremo de la metamorfosis de la imagen social del ingeniero, permaneció la intención de sumar y sumar aspectos que definieran la concreción de una personalidad grupal que les otorgara los sentidos de unidad y trascendencia (García, 2008) en la nación, o un ethos (Weber, 2006) que les diera cohesión en el sentido propuesto por Scandroglio, López y San José (2008) en la siguiente nota:
(...) sería aquel que a través de un proceso de autocategorización ha producido mediante la despersonalización, una constelación de efectos que incluyen conformidad grupal, diferenciación intergrupal, percepción estereotípica, etnocentrismo y actitud positiva hacia los miembros del grupo. (p.82)

Entre los aspectos de esa personalidad grupal o ethos se han venido señalando intercaladamente algunos que ahora es imprescindible enunciar con detenimiento, ellos fueron: aptitud hacia las ciencias exactas, actitud favorable por el trabajo manual y práctico, inclinación por la observación y la experimentación, vocación por la curiosidad, interés por la manipulación de máquinas y herramientas y culto por el progreso material. Pero nada más ilustrativo del conjunto anterior de atributos de la personalidad colectiva que el punto de vista expuesto por el ingeniero y político chileno Alejandro Bertrand Huillard (1854-1942) a finales del siglo XIX al organizar este vademécum de cualidades del ingeniero: "Espíritu científico, tendencia a la lógica matemática, habilidad manual, gráfica y ejecutiva, espíritu organizador constructivo, instinto del manejo de colectividades, afición natural a la industriosidad" (Bertrand como se citó en Parada, 2011, p. 59).

Aspectos a los que se les sumaría, a medida que el siglo XIX expiraba, la cualidad del gusto por el aprendizaje de conceptos y principios administrativos y económicos, toda vez que creían que el ingeniero debería abrirse camino en el terreno de la gestión empresarial y pública (Parada, 2011). Por eso, no extraña que hacia 1910 en Chile los ingenieros Carlos Hoerning y Guillermo Subercaseaux Pérez (1872-1959) trabajaron por la inclusión de la cátedra de Economía Política en el plan de estudios de la Ingeniería. En Colombia idéntica campaña 
emprendieron los ingenieros Pedro Nel Ospina Vásquez, Tulio Ospina Vásquez (Safford, 2014) y Alejandro López Restrepo (López, 2011) en la Facultad de Minas de la Universidad de Antioquia.

\section{La búsqueda de reconocimiento social de la ingeniería en Colombia}

La ingeniería ingresa en el concierto cultural y económico-ocupacional de Colombia por la misma ruta de las demás naciones de América Latina: la fórmula liberal de expansión económica al lado de las exportaciones de bienes primarios mineros y agropecuarios en dirección al mercado europeo y luego norteamericano, que puso en la agenda pública requerimientos de orden científico, tecnológico, educativo y logísticos que estaban ralentizados o a los que apenas estaba dándosele algún grado de importancia desde la apertura comercial del siglo XVIII en el marco de las reformas estructurales borbónicas emprendidas por Felipe V y Carlos III para remozar el desvencijado imperio ibérico (Torrejano, 2010b) o estimular su expansión económica sobre "las posibilidades inmediatas y de largo plazo de la economía colonial" (Stanley y Stein, 1981, p. 17) y acometer la tarea de recentralización del poder monárquico (Véliz, 1984).

Entre dichos requerimientos cabe resaltar dos que se alimentan mutuamente: la falta de información abundante y fidedigna acerca de la existencia y la localización de nuevas fuentes de recursos naturales y alimentos demandados por el creciente mercado mundial, y la exigua cantidad de personas con formación científica y técnica en las disciplinas pertenecientes al campo de las ciencias naturales y exactas para el respectivo mejoramiento de su extracción o la cualificación de la técnica y las maquinas empleadas en su obtención, que para nuestra economía no era diferente a avanzar en el hallazgo de yacimientos de oro (Colmenares, 1991; Jaramillo, 1991), la producción de tabaco, la extracción de quina y el cultivo y beneficio del café en el siglo XIX (Ocampo, 1998, 2010).

Este cuello de botella empieza a destruirse con el emprendimiento de acciones icónicas que datan de finales del siglo XVIII como: la apertura de la cátedra de Matemáticas por José Celestino Mutis el 13 de marzo de 1762 en el Colegio Mayor de Nuestra Señora del Rosario con la presencia del virrey Mesía de la Zerda, su familia y el cabildo (Torrejano, 2012); la realización de la Expedición Botánica de 1873 a 1815; el plan de reforma educativa del oidor Francisco Antonio Moreno y Escandón, impulsado pocos años después por el arzobispo virrey Caballero y Góngora (Torrejano, 2010a, 2011, 2012); la misión de ingenieros de minas contratada en Sajonia por el rey Carlos III y enviada al virreinato de la Nueva Granada en 1788 con el fin de buscar minas de plata (Poveda,1993), que formaban "los señores Emannuel Gottlieb, Cristian Frederich Klem, Jacob Benjamin Wiesner, Johann Abraham, Friederich Ningertz y Joachim Bayer" (Poveda, 1993, p. 51); la creación en 1801 de la Escuela de Ciencias Físicas y Matemáticas; la fundación de la Universidad de San Pedro Apóstol de Mompox por 
En búsqueda de la identidad social del ingeniero: una trayectoria de construcción de identidad profesional en Colombia...

Real Cédula del 4 de noviembre de 1804 (Torrejano, 2010a); la creación por Juan del Corral en 1814 del Colegio Militar de Ingenieros; la misión en mineralogía e ingeniería de Rivero y Boussingault establecida mediante Ley del 28 de julio de 1823 (Poveda, 1993); la instauración del Colegio Militar por Ley 6 de 1847, aunque inició labores el 2 de enero de 1848 bajo la dirección de los generales José María Ortega y Joaquín Barriga; la erección de la Comisión Corográfica; el establecimiento de la Universidad Nacional en la Ley 66 del 22 de septiembre de 1867; la constitución de la Escuela de Minería de la Universidad de Antioquia y la fundación de la Sociedad Colombina de Ingenieros en 1887, entre otros.

Empero, el cuello de botella no terminaría por deshacerse tan fácilmente. Además de los hitos educativos y académicos, la economía nacional francamente era hostil a la profesión de ingeniero por cuenta de la existencia de sectores que funcionaban con pocas o ninguna innovación tecnológica. El sector primario dominaba el mundo de la producción y la exportación, siendo la minería de metales preciosos el negocio en el que empresarios nacionales, pero sobre todo, extranjeros, introdujeron ciertas sofisticaciones; en la agricultura comercial de exportación los polivalentes propietarios nacionales de latifundios le apostaron a la producción de café (hasta las postrimerías del siglo XIX en la región centro oriental) o al tabaco, sin que se desplegara capacidad creativa aplicada en el perfeccionamiento o la transformación de los métodos de producción, el mejoramiento de la calidad de un bien, el perfeccionamiento de la técnica organizativa empresarial o el ajuste de la relaciones sociales de trabajo (Kalmanovitz, 1984, 1997, 2010; Ocampo, 1998; Guerrero y Avellaneda, 2003; Posada, 2003; Valencia, 2003a, 2003b).

De esta manera, en los países más desarrollados de Europa y Estados Unidos de América los acontecimientos que reclamaron la presencia del ingeniero moderno fueron: la construcción de líneas ferroviarias, la implementación de caminos para ruedas, el levantamiento de nuevos puentes ensamblados con hierro forjado; el crecimiento de la ciudades, que dio lugar al ensanche y la construcción de acueductos públicos; la navegación fluvial y marítima a vapor; la ampliación de la siderurgia; el aumento de la industria textil y la revolución mecánica de la agricultura (Poveda, 1993). En Colombia, la demanda laboral por un profesional asociado con la modernización capitalista provendría, al igual que en el resto de países de América Latina, de los efectos modernizadores de la articulación con el mercado internacional (Contreras y Cueto, 2008; Parada, 2011; López, 2012; Salerno, 2015; Tanamachi y Ramos, 2015) sintiéndose sobre todo en el desarrollo de la infraestructura de transporte: navegación fluvial a vapor por el río Magdalena (Zambrano, 1979; Melo, 1991; Viloria, 2000; Ocampo, 2015), ferrocarriles y carreteras (Salazar, 2000; Pachón y Ramírez, 2006; Safford, 2010, 2014), obras públicas de provisión de algunos servicios públicos en las ciudades principales y la naciente industria de bienes de consumo (Arango,1979; Echavarria,1999; Montenegro, 2002; Kalmanovitz, 2010; Ocampo, 2015). 
Todo esto llevaría a la adaptación del sistema educativo nacional desde la mitad del siglo XIX, con el ofrecimiento de la carrera de Ingeniería en un sinuoso proceso que Mayor (2012) y Safford (2014) datan de las postrimerías de la década de 1840, al tenor de la fundación del Colegio Militar en 1848, y de finales de la década de 1860 con el establecimiento del Colegio Militar y la Escuela Politécnica (1861-1866), que nos regaló la separación de la ingeniería civil de la ingeniería militar. Poveda (1993), por su parte, ubica el origen de la transformación en la segunda década del mismo siglo (1814), en plena campaña independentista y redacción de constituciones regionales (Pombo y Guerra, 1986), con la creación del Colegio Militar de Ingenieros de Rionegro (Antioquia) bajo la dirección de Francisco José de Caldas y la orientación militar del francés Manuel Roergas Serviez, fenómeno político que a la postre impidió su funcionamiento.

Con la generación de las circunstancias económicas que impulsaban la demanda de ingenieros y el sistema educativo adaptándose a sus requerimientos, podría pensarse que hubo un movimiento sincrónico que posicionaría la profesión y la formación de identidad social. Sin embargo, la realidad fue menos armónica y más atonal, quizá porque la demanda laboral de los sectores modernos fue restringida y la oferta de profesionales, con todo y lo limitada que era todavía, desencadenaría un desfase entre la oferta y la demanda que concluyó con la desocupación de un grupo indeterminado de egresados que no vieron opción distinta a la de trabajar en áreas y sectores para los que no se prepararon (Safford, 2014), y valió la publicación, en el segundo número de la revista Anales de Ingeniería, de un artículo escrito por el ingeniero Carlos Téllez en el que describió este problema con las siguientes palabras:

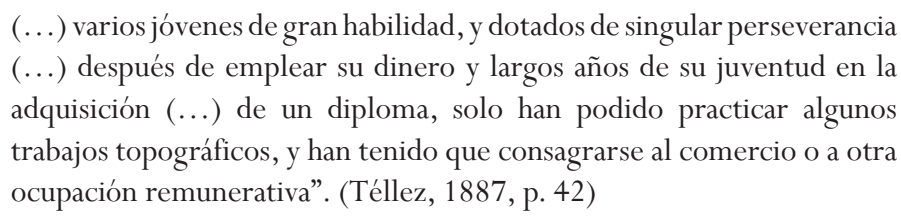

Fenómeno que se acentuaría con la preferencia que los empresarios extranjeros y nacionales tuvieron por la contratación de ingenieros foráneos, con los argumentos de que ellos disponían de una extensa experiencia y amplios y actualizados conocimientos teóricos y prácticos, actitud que a la postre influiría en la búsqueda de identidad colectiva en torno a la discriminación profesional de la que eran objeto (Safford, 2014), semejando el proceso discurrido en América Latina.

\section{La cruzada identitaria del ingeniero colombiano}

Antes de tipificar los rasgos característicos de la personalidad colectiva establecida y exhibida por los ingenieros colombianos es prudente indicar que hay un elemento de conformación 
En búsqueda de la identidad social del ingeniero: una trayectoria de construcción de identidad profesional en Colombia...

y representación simbólica que cobija a todos los universitarios graduados en el país, que equivale a anotar que sin importar la particular formación académica y ocupacional que desempeñaran los profesionales, todos fueron parte de un gran conjunto: el de los "letrados", concepto que facturó el rector de la Universidad Nacional de Colombia, Manuel Ancízar, en la sesión de clausura del año escolar de 1869, con el que dibujaría el contorno ético de cuño cívico que traería la condición de individuo dotado de ilustración y sapiencia. Estas fueron sus apreciaciones al respecto:

difunde la verdad instruyendo al ignorante; tal es la obligación adscrita al
título de letrado con que os honrareis en breve; tal la indemnización que
debéis a la patria por el beneficio que de ella recibís. Podréis enaltecerla
ilustrándola (...). (Ancízar como se citó en Villegas, 2004, p. 6)

Como se aprecia, el profesional es invitado a que priorice el servicio a la nación sobre las consideraciones de estricto orden personal o, inclusive, gremial. Hay un argumento de orden ético que estima que la educación superior es un bien intangible e inconmensurable que le confiere al graduado un espacio social de representación y estatus que en lugar de su encumbramiento lo conduzca a convertirse en un aventajado que fabrica ideas y proyectos en favor de la sociedad.

Convocatoria que quizá pueda leerse con la partitura de una tonada que invita a diferentes sectores de la sociedad colombiana a reflexionar sobre la bondad del proyecto de fomentar la educación formal de la juventud y la inconveniencia de medirla con el rasero del alto costo de oportunidad que tenía enviar a los jóvenes a la escuela y la universidad (Ramírez y Salazar, 2010; Torrejano, 2012), pues preferían que aprendieran de negocios o un oficio en la práctica misma de sus empresas o contratados por recomendación en la de algún conocido (Deas, 2003).

Otros jóvenes, en cambio, desestimaron la voluntad de sus acaudalados padres para cursar estudios universitarios y prefirieron empaparse desde los gajes del negocio en la práctica misma como lo revela la experiencia de Juan De Francisco Martín (1799-1869), quien "no obstante haber tenido la oportunidad de recibir una formación universitaria en Europa (...) se dedicaría más bien al comercio aprovechando la experiencia y las conexiones de su padre” (Bell y Ripoll, 2003, p. 320), o la del destacado comerciante sangileño con sede comercial en Bogotá Francisco Vargas Vargas, hijo varón mayor de Inocencio Vargas, que a la edad de 21 años prefirió el aprendizaje como "autodidacta en el comercio" (Safford, 2003, p. 385). Aún así, las consideraciones de este sector de destacada posición social y económica no desdibuja la presencia, desde finales del siglo XVIII, de la concepción de la importancia de la educación en el seno de la clase rica (Safford, 2003; Silva, 2004; Torrejano, 2010a), tanto que Safford (2003) propone que cuando una familia disponía de miembros con educación superior refrendaba su pertenencia a la clase alta o al "notablato". 


\section{Elementos aglutinadores de la identidad del ingeniero colombiano}

La edificación de identidad fue un proceso que significó la concreción de cierto número de valores corporativos que se forjaron antes y después de la organización de su respectivo gremio, la Sociedad Colombiana de Ingenieros en 1887, sin que este hito trastocara la línea de identidad colectiva dibujada desde los albores de la vida republicana. Los valores institucionales o corporativos que a manera de elementos aglutinadores o cohesionadores (García, 2008) se destacaron fueron: a) mostrarse en la perspectiva de héroes sociales que encarnaban la revolución de la modernización (Anderson, 1998; Giraldo, 1998; Melo, 1998) y la modernidad en perspectiva del ensayo de una "experiencia vital" (Berman, 1989); b) estimarse campeones de un movimiento intelectual que exalta la filosofía natural, en el plano de la ciencias naturales y exactas aplicadas, sumergidas en un espíritu ilustrado y pragmático que "busca crear una práctica científica local y por transformar las instituciones académicas superiores” (Melo, 1998, p. 231); y c) resaltar la idoneidad académica y la experiencia como argumentos de legitimidad profesional que los colocaba en pie de igualdad con los ingenieros extranjeros en el momento de la contratación laboral.

Con algo de detalle el primero de los valores listado es el que le da consistencia al plan de reconocerse y hacerse reconocer en la sociedad en sincronía con el devenir del tiempo, la ilusión de conducir la estructura económica pre-moderna hacia la modernidad tecnológica de máquinas sofisticadas movidas por fuerza motriz mecánica, etc. (Téllez, 1887).

Dicha conducción adquirió forma social en el ideal práctico de ser ellos el grupo ocupacional idóneo para la obtención de expansión economía por la vía de la explotación de recursos naturales, el control de fuentes energéticas y la puesta a tono de la infraestructura de transporte, palabras más palabras menos, por su función estratégica en el desarrollo del capitalismo (Rueda, 1888).

Función que, en opinión del ingeniero Abelardo Ramos, cofundador de la revista Anales de Ingeniería, tendría que romper con el marasmo del cuerpo profesional frente a la misión histórica de convertirse en un órgano de consulta técnica del Gobierno nacional centralizado (Constitución de 1886). Así, la intención estratégica de la corporación era posicionar al gremio en calidad de tecnocracia (Ramos, 1887).

En lo que toca al segundo aspecto vale decir que velaron por la vida del quadrivium aplicado, el espíritu chartrense (renacimiento cultural del siglo XII) o el eco ilustrado de carácter positivista de la ciencia, cuestión que bien la retrató el político conservador Mariano Ospina Rodríguez con la crítica que le haría a la orientación academicista y retórica del sistema educativo imperante en Colombia a mediados del siglo XIX: 
En búsqueda de la identidad social del ingeniero: una trayectoria de construcción de identidad profesional en Colombia...

\begin{abstract}
las matemáticas, las ciencias físicas y naturales, la geografía, la historia, la literatura no eran materia de enseñanza en ese curso ni en ningún otro. Nada era más común entonces que ver un bachiller en filosofía (...) que no sabía hacer una suma de números enteros. (Ospina, 1969, p. 126)
\end{abstract}

Filosofía que impactaría su propia vida familiar cuando escogió para sus hijos Tulio y Pedro Nel Ospina Vásquez la profesión de ingeniero por su demostrada grafía útil, permitiéndoles en el futuro amasar dividendos personales y contribuir al progreso nacional. Veamos una parte de este punto de vista:

\begin{abstract}
hay ciencias muy atractivas, pero poco provechosas, como la Botánica, la Zoología y la Astronomía, que deben dejarse a los ricos, y en el mismo caso se halla la Literatura. Religión y moral cuanta les quepa en el alma y en el cuerpo; ciencia aplicable y aplicada, muchísima (...) ciencia puramente especulativa, literatura e idiomas muertos, algo; novelas y versos, nada. (Vernaza, 1935, p.18)
\end{abstract}

En esta perspectiva, los ingenieros trabajaron en demostrar que se caracterizaban por poseer el espíritu de la aplicación de los conocimientos teóricos, que eran más que sapiencia abstracta condensada en teoremas, ecuaciones o fórmulas, pues habían puesto sus energías, entre otras inquietudes, en la experimentación de materiales de construcción acordes con los requerimientos y materiales disponibles en el país (Peña, 1888) y la publicación de material bibliográfico de matemáticas y geometría inédito que se utilizaría en la enseñanza secundaria y universitaria.

Producción intelectual en la jurisdicción cultural de lo que Burke (2013) denomina conocimiento público, ese que abandona el restringido espacio de un grupo elitista particular y coincide con el sutil desarrollo de la industria de la imprenta y las editoriales, tratándose de un paso adelante en la mercantilización del conocimiento o la explotación económica de las ideas, en combinación con el fortalecimiento del sentido de propiedad intelectual en forma de derechos de autor y en el caso de la experimentación de materiales con las patentes, proceso que data, a nivel mundial, de finales del siglo XV en Italia (Burke, 2013).

En el tercer aspecto, en concordancia con las preocupaciones de los ingenieros latinoamericanos, estuvo presente la sensación de inconformidad derivada de la actitud preferente de los empleadores públicos y privados por los profesionales extranjeros, amparados en el argumento de la inexperiencia de los ingenieros criollos en el diseño y la ejecución de grandes obras públicas y de infraestructura de transporte, ya que en "ellas sólo ocasionalmente y en aislamiento individual, han figurado algunos ingenieros colombianos” (Ramos, 1887, p. 8). 
La desconfianza generalizada hacia el trabajo del profesional colombiano hizo que al principio, de manera espontánea, y, luego, de forma metódica y sistemática, a partir de la creación de la Sociedad Colombiana de Ingenieros, se dieran a la misión de acreditar la formación y experticia asimilada mediante el ejercicio de una práctica ocupacional denodada, casi que al tenor de un eslogan corporativo nunca enunciado de "también lo hacemos bien".

\section{Conclusión}

El posicionamiento de la profesión de ingeniero moderno en Colombia corrió por cuenta del avance del particular proceso nacional de desarrollo del capitalismo en el marco de la articulación al mercado internacional desde la producción y exportación de alimentos, materias primas y metales preciosos en pleno auge de la concepción liberal del mercado, en búsqueda del mecanismo que permitiera la expansión de la economía nacional.

Este posicionamiento estuvo marcado por vicisitudes provenientes, de manera particular, de la condición de periferia en la inserción al mercado mundial y su carga de falta de capital y la penuria del erario para adelantar con intensidad y celeridad los trabajos materiales de adecuación de la estructura y la infraestructura económica propia de una economía rural, agropecuaria y minera en la que dominaban métodos, técnicas, tecnología y relaciones de trabajo atrasadas, todo un escenario que en lugar de invitar al desarrollo de la ingeniería lo interrumpía, disonancia temporal que nunca detuvo el empeño social de algunos sectores de la dirigencia y el empresariado nacional de organizar el alma mater que formara a los profesionales sobre los que tendría que recaer el peso de impulsar y sostener el desarrollo capitalista moderno.

El impulso a la formación de ingenieros modernos en Colombia y América Latina, vino de la mano con un paquete de referencias históricas y conceptuales provenientes del llamado renacimiento cultural del siglo XII anclado en la enseñanza de las ciencias exactas y naturales, que creció con el racionalismo y utilitarismo ilustrado empoderado de la idea de sacarle provecho material a los conocimientos teóricos y conceptuales o su valoración en función de su aporte al progreso de la humanidad.

Precisamente, esta trayectoria histórica universal sedujo la mentalidad de los ilustrados gobernantes nacionales, dándose rápidamente a la empresa de establecer, desde mediados del siglo XIX, los primeros centros de formación especializada (Colegio Militar de 1847), punto de inflexión, y si se quiere icónico, en el posterior empeño por forjar un sentido de identidad colectiva o autodefinición con el cual reclamar una posición de prestigio en la sociedad colombiana.

Los aspectos relevantes de dicho proceso de autodefinición se desarrollaron alrededor de tres elementos aglutinadores: 1) la función modernizadora económica, 2) la función modernizadora 
En búsqueda de la identidad social del ingeniero: una trayectoria de construcción de identidad profesional en Colombia...

cultural y científica, y 3) el combate por destruir la asimetría ocupacional que le daba a los ingenieros extranjeros prevalencia en la contratación.

\section{Referencias}

Anderson, P. (1998). Modernidad y revolución. En F. Viviescas. y F. Giraldo. (Eds.), Colombia: el despertar de la modernidad (pp.67-89). Bogotá, Colombia: Foro Nacional por Colombia.

Arango, M. (1979). Café e Industria 1850-1930. Bogotá, Colombia: Carlos Valencia Editores.

Bell, G. y Ripoll, M. (2003). Los herederos del poder: Juan De Francisco Martín 1799-1869. En C. Dávila. (Ed.), Empresas y empresarios en la Historia de Colombia siglos XIX y XX (pp. 317-351). Bogotá, Colombia: Norma - Universidad de los Andes.

Berman, M. (1989). Todo lo sólido se desvanece en el aire, la experiencia de la modernidad. Buenos Aires, Argentina: Siglo XXI.

Bertola, L. y Ocampo, J. (2016). El desarrollo económico de América Latina desde la independencia. México, D. F., México: Fondo de Cultura Económica.

Burke, P. (2013). Historia social del conocimiento, de Gutenberg a Diderot. Barcelona, España: Paidós Orígenes.

Colmenares, G. (1991). La formación de la economía colonial. En J. Ocampo. (Ed.), Historia económica de Colombia (pp. 13-46). Bogotá, Colombia: Siglo XXI y Fedesarrollo.

Contreras, C. y Cueto, M. (2008). Caminos, ciencia y Estado en el Perú 1850-1930. Historia, Ciencias, Saúde, 15 (3), 635-655.

Dávila, C. (Ed.). (2003). Empresas y empresarios en la Historia de Colombia siglos XIX y XX. Bogotá, Colombia: Norma - Universidad de los Andes.

Deas, M. (2003). Retrato de un hombre hecho a sí mismo: la vida del santandereano Juan Crisóstomo Parra escrito por Daniel Cote. En C. Dávila. (Ed.), Empresas y empresarios en la Historia de Colombia siglos XIX y XX (pp. 353-374). Bogotá, Colombia: Norma Universidad de los Andes.

De la Torre, F. (2002). Profesionalización de la ingeniería en el occidente de México durante el siglo XIX: el caso de Jalisco. Quadens D'Historia de L'Enginyeria, 5, 147-155.

Domínguez, R. (2013). La ingeniería civil en México 1900-1940, análisis histórico de los factores de su desarrollo. México D. F., México: Universidad Nacional Autónoma de México.

Durkheim, E. (1893). La división del trabajo social. Recuperado de www.fmmeducacion.com.ar

Echavarria, J. (1999). Crisis e industrialización, las lecciones de los treintas. Bogotá, Colombia: Tercer Mundo - Banco de la República - Fedesarrollo. 
García, A. (2008). Identidades y representaciones sociales: la construcción de las minorías. Revista Crítica de Ciencias Sociales y Jurídicas, 18 (2), 211-222.

Giraldo, F. (1998). La metamorfosis de la modernidad. En F. Viviescas. y F. Giraldo. (Eds.), Colombia: el despertar de la modernidad (pp.248-310). Bogotá, Colombia: Foro Nacional por Colombia.

Glade, W. (1991). América Latina y la economía internacional 1870-1914. En L. Bethell. (Ed.), Historia de América Latina: Economía y Sociedad 1870-1930 (pp. 1-49). Barcelona, España: Crítica.

Guerrero, A. y Avellaneda, M. (2003). La élite empresarial de Santander 1880-1912. En C. Dávila. (Ed.), Empresas y empresarios en la Historia de Colombia siglos XIX y XX (pp. 143-177). Bogotá, Colombia: Norma -Universidad de los Andes.

Hale, C. (1991). Ideas políticas y sociales en América Latina 1870-1930. . En L. Bethell. (Ed.), Historia de América Latina: Cultura y Sociedad 1830-1930 (pp. 1-64). Barcelona, España: Crítica.

Jaramillo, J. (1991). La economía del virreinato 1740-1810. En J. Ocampo. (Ed.), Historia económica de Colombia (pp. 49-83). Bogotá, Colombia: Siglo XXI y Fedesarrollo.

Kalmanovitz, S. (1984). El régimen agrario durante el siglo XIX en Colombia. En J. Jaramillo. (Ed.), Manual de Historia de Colombia (pp. 211-319). Bogotá, Colombia: Procultura.

Kalmanovitz, S. (1997). Economía y nación: una breve historia de Colombia. Bogotá, Colombia: Tercer Mundo Editores.

Kalmanovitz, S. (2010). Nueva Historia Económica de Colombia. Bogotá, Colombia: Universidad Jorge Tadeo Lozano.

Le Goff, J. (2008). Los intelectuales en la Edad Media. Barcelona, España: Gedisa.

Lynch, J. (1987). Hispanoamérica 1750-1850, ensayos sobre la sociedad y el Estado. Bogotá, Colombia: Universidad Nacional.

López, A. (2011). El trabajo, nociones fundamentales. Medellín, Colombia: EAFIT.

López, J. (2012). Historia de la Universidad Nacional de Ingeniería, los años fundacionales 1876 1909. Lima, Perú: Editorial de la Universidad Nacional de Ingeniería.

Mayor, A. (2002). La Escuela Nacional de Minas de Medellín y los orígenes de la estadística en Colombia 1900-1940. Revista Colombiana de Estadística, 25 (2), 73-96.

Melo, J. (1991). Las vicisitudes del modelo liberal 1850-1899. En J. Ocampo. (Ed.), Historia económica de Colombia (pp. 115-171). Bogotá, Colombia: Siglo XXI y Fedesarrollo. 
En búsqueda de la identidad social del ingeniero: una trayectoria de construcción de identidad profesional en Colombia...

Melo, J. (1998). Algunas consideraciones globales sobre modernidad y modernización. En F. Viviescas. y F. Giraldo. (Ed.), Colombia: el despertar de la modernidad (pp.225-247). Bogotá, Colombia: Foro Nacional por Colombia.

Montenegro, S. (2002). El arduo tránsito hacia la modernidad: historia de la industria textil colombiana durante la primera mitad del siglo XIX. Medellín, Colombia: Norma - Universidad de Antioquia - Universidad Nacional sede Medellín - Universidad de los Andes.

Ocampo, J. A. (1998). Colombia y la economía mundial 1830-1910. Bogotá, Colombia: Tercer Mundo, Fedesarrollo y Colciencias

Ocampo, J. A. (2010). El sector externo de la economía colombiana en el siglo XIX. En A. Meisel. y M. Ramírez. (Eds.), Economía colombiana del siglo XIX (pp. 201-240). Bogotá, Colombia: Fondo de Cultura Económica.

Ocampo, J. A. (2015). Café, industria y macroeconomía: ensayos de historia económica colombiana. Bogotá, Colombia: Fondo de Cultura Económica.

Ospina, M. (1969). Escritos sobre economía y política. Bogotá, Colombia: Universidad Nacional de Colombia.

Pachón, A. y Ramírez, M. (2006). La infraestructura de transporte en Colombia durante el siglo XX. Bogotá, Colombia: Fondo de Cultura Económica.

Parada, J. (2011). La profesión de ingeniero y los Anales del Instituto de Ingenieros de Chile 18401927. Recuperado de https: / / users.dcc.uchile.

Peña, M. (1888). Cimiento romano. Anales de Ingeniería, 1 (6), 175.

Pombo, M. y Guerra, J. (1986). Constituciones de Colombia. Bogotá, Colombia: Banco Popular.

Posada, E. (2003). Empresarios y ganaderos en la Costa Atlántica 1850-1950. En C. Dávila. (Ed.), Empresas y empresarios en la Historia de Colombia siglos XIX y XX (pp. 63-81). Bogotá, Colombia: Norma - Universidad de los Andes.

Poveda, G. (1993). Historia social de la ciencia en Colombia, Ingeniería e historia de las técnicas. Bogotá, Colombia: Colciencias.

Ramírez, M. y Salazar, I. (2010). El surgimiento de la educación en Colombia: ¿En qué fallamos? En A. Meisel. y M. Ramírez. (Eds.), Economía colombiana del siglo XIX (pp. 419469). Bogotá: Colombia, Fondo de Cultura Económica.

Ramos, A. (1887). Origen de la Sociedad Colombiana de Ingenieros. Anales de Ingeniería, 1 (1), 8 .

Rueda, M. (1888). Nuestra voz de año nuevo. Anales de Ingeniería, 1 (6), 162. 
Safford, F. (2003). El comercio de importación en Bogotá en el siglo XIX: Francisco Vargas, un comerciante de corte inglés. En C. Dávila. (Ed.), Empresas y empresarios en la Historia de Colombia siglos XIX y XX (pp. 375-406). Bogotá, Colombia: Norma - Universidad de los Andes.

Safford, F. (2010). El problema de los transportes en Colombia. En A. Meisel. y M. Ramírez. (Eds.), Economía colombiana del siglo XIX (pp. 523-570). Bogotá, Colombia: Fondo de Cultura Económica.

Safford, F. (2014). El ideal de lo práctico, el desafío de formar una élite técnica y empresarial en Colombia. Medellín, Colombia: Universidad EAFIT.

Salazar, J. (2000). De la mula al camión, apuntes para una historia del transporte en Colombia. Bogotá, Colombia: Tercer Mundo Editores.

Salerno, E. (2015). Los ingenieros, la tecnocracia de los ferrocarriles del Estado. Revista H-Indistri@, 9 (16), 13-34.

Scandroglio, B., López, J. y San José, M. (2008). La teoría de la identidad social: una síntesis crítica de los fundamentos, evidencias y controversias. Revista Psicothema, 20 (1), 80-89.

Silva, M. (Ed.). (2007). El Ochocientos: profesiones e instituciones civiles. Zaragoza, España: ARPI Relieve.

Silva, R. (2004). Saber, cultura y sociedad en el Nuevo Reino de Granada, siglos XVII y XVIII. Medellín, Colombia: La Carreta.

Smith, A. (Sin Fecha). La riqueza de las naciones. Recuperado de www.uv.es

Spencer, H. (Sin Fecha). Origen de las profesiones. Recuperado de www.reis.cis.es

Stanley, J. y Stein, B. (1981). La herencia colonial de América Latina. México, D. F., México: Siglo XXI.

Tanamachi, G. y Ramos, M. (2015). La Escuela Nacional de Ingenieros y las ciencias físicas en los albores del siglo XX. Revista Mexicana de Investigación Educativa, 20 (65), 557-580.

Téllez, C. (1887). Labores para el ingeniero en Colombia. Anales de Ingeniería, 1 (2), 42.

Torrejano, R. (2010a). La educación a finales del periodo colonial 1887-1806: entre lo útil y lo inútil. Revista Universidad EAFIT, 46 (158), 64-81.

Torrejano, R. (2010b). Las reformas económicas y políticas borbónicas: certeza e incertidumbre en una época convulsionada. Revista Republicana, (8), 93-108

Torrejano, R. (2011). Ruta de una reforma: la educación entre el plan de Antonio Moreno y Escandón y la reforma de Francisco de Paula Santander. Revista Mutis, 1(1), 47-73. 
En búsqueda de la identidad social del ingeniero: una trayectoria de construcción de identidad profesional en Colombia...

Torrejano, R. (2012). Historia de la educación en Colombia, un siglo de reformas 1762-1870. Bogotá, Colombia: Temis - Corporación Universitaria Republicana.

Valbuena, P. (1996). Historia de la Escuela Técnica Superior de Ingenieros Industriales de Madrid. Recuperado de http://www.oa.upm.es

Valencia, A. (2003a). El empresario en el antiguo departamento de Caldas 1850-1930. En C. Dávila. (Ed.), Empresas y empresarios en la Historia de Colombia siglos XIX y XX (pp. 85-1087). Bogotá, Colombia: Norma - Universidad de los Andes.

Valencia, A. (2003b). Las prácticas empresariales en el Estado Soberano del Cauca. En C. Dávila. (Ed.), Empresas y empresarios en la Historia de Colombia siglos XIX y XX (pp. 111-140). Bogotá, Colombia: Norma - Universidad de los Andes.

Véliz, C. (1984). La tradición centralista de América Latina. Barcelona, España: Ariel.

Vernaza, J. (1935). Biografía del general Pedro Nel Ospina. Cali, Colombia: Editorial América.

Viloria, J. (2000). Empresarios de Santa Marta: el caso de Joaquín y Manuel Julián de Mier 18001896. Cartagena, Colombia: Banco de la República.

Villegas, L. (2004). El tortuoso camino hacia la autonomía. En E. Restrepo. (Ed.), La Universidad Nacional en el siglo XIX, documentos para su historia (pp. 41-55). Bogotá, Colombia: Universidad Nacional de Colombia.

Weber, M. (2006). Ética protestante y el espíritu del capitalismo. México, D. F., México: Éxodo.

Zambrano, F. (1979). La navegación a vapor por el río Magdalena. Anuario Colombiano de Historia Social y de la Cultura, (9), 63-75. 